\title{
Investigation on the Oxides Morphology of Fe-Based Amorphous Ribbons
}

\author{
Wang Jian, Shulan Zhang \\ AT\&M-NARI Amorphous Technology Co., \\ Ltd, Beijing 100081, \\ China \\ shlzhang_cisri@sina.com
}

\begin{abstract}
The oxidation behavior of the amorphous ribbons heat treated under different temperature and holding time was deeply investigated. The oxidation morphology was observed by using of SEM equipment. The experiment results show that at the initial stage of oxidation, the morphology of the oxides is small round particles. With the holding time increasing, the small round oxides began to gather into a larger oxide. What's more, the amount of the oxides increased. Besides, the experiment results also proved that the existence of the impurity and defects accelerate the oxidation and the morphology is also round particles. Increasing the heat treatment temperature, part of the oxidation morphology changed, some cracks formed in the oxides. Altogether, the occurrence of the oxidization made the magnetic properties of the amorphous ribbons deteriorate.
\end{abstract}

Keywords_- oxidation; morphology; amorphous ribbons

\section{INTRODUCTION}

Up to now, the oxidation of amorphous materials was widely investigated, such as bulk metallic glass and Fe-based amorphous ribbons [1-4]. The oxidation scales for the Fe based bulk metallic glass consisted mainly of boron oxide $\left(\mathrm{B}_{2} \mathrm{O}_{3}\right)$ and minor amounts of iron oxides $\left(\mathrm{Fe}_{3} \mathrm{O}_{4} / \mathrm{FeO}\right)$. Particularly, the $\mathrm{B}_{2} \mathrm{O}_{3}$ benefit for the decreased oxidation rates as compared to those of crystalline counterpart. on the other words, the oxidation rate of the bulk amorphous alloys is much slower than those of crystalline alloys at $600-700{ }^{\circ} \mathrm{C}$.For the amorphous $\mathrm{Fe}_{78.5} \mathrm{~B}_{13} \mathrm{Si}_{8.5}$ alloy ribbon, selective oxidation occurred when it was annealed in an $\mathrm{H}_{2}-\mathrm{H}_{2} \mathrm{O}$ atmosphere and form the depletion of the element boron, which caused the decrease of the crystalline temperature. However, the existence of the crystallization for the amorphous ribbons can deteriorate its magnetic properties. Thus, the addition of element carbon was tried to reduce depletion of the boron and the thickness of the oxide film. Altogether, the investigation on oxidation of the amorphous alloys mainly focused on the oxidation mechanism and its effect on the crystallization. However the morphology of the oxides were seldom studied, thus in his paper, the morphology was investigated for the amorphous ribbons annealed under different temperature and holding time. It is well known that the amorphous ribbons $\mathrm{Fe}_{78} \mathrm{Si}_{9} \mathrm{~B}_{13}$ are widely used in the power system. The annealing is an inevitable process for the ribbon to decrease stress formed during manufacture. During this course whether oxidation occurs and

The paper was sponsored by the natural science foundation of china (No. 51374080). the extent of the oxidation has not been reported. Due to the importance of the effect of the oxidation on the magnetic properties, the oxidation of the amorphous ribbon must be investigated deeply.

\section{EXPERIMENT}

$\mathrm{Fe}_{78} \mathrm{Si}_{9} \mathrm{~B}_{13}$ amorphous ribbons were chosen as the experimental material. The sample size is $30 \mathrm{~mm} \times 300 \mathrm{~mm}$. The samples were annealed under different holding temperature and holding time in the air with relative humidity $67 \%$. The magnetic current was 100A. When the samples furnace cooled to $150^{\circ} \mathrm{C}$, the power was turned off, then air cooled to ambient temperature in the air. The holding temperature is $360^{\circ} \mathrm{C}$, $370^{\circ} \mathrm{C}, 380^{\circ} \mathrm{C}$ and the holding time is $30 \mathrm{~min}, 480 \mathrm{~min}$ respectively. After heat treatment, the samples surface was observed by SEM to analyze the effect of annealing temperature and holding time on the oxidation morphology of the amorphous ribbons. What's more, the chemical compositions of the oxidation of the treated ribbon and quenched ribbon were measured by EDS. According to the result, the oxidation morphology and its effect on magnetic properties were discussed.

\section{RESULT AND ANALYSIS}

\section{A. Morphology}

Fig. 1 shows the surface morphologies of the ribbon annealed at different temperature for $30 \mathrm{~min}$. It can be seen that at lower temperature $360^{\circ} \mathrm{C}$ the white particles began to form. With the increase of annealing temperature, the particles begin to grow. Particularly, some round small particles formed around the larger particles. It is because that the oxides nucleate around the formed oxides. On the other words, the former formerly oxides offer the nucleation location for the new oxides. The results also imply that once the oxidation happen, the oxides grow faster. Fig. 1 also reveals that oxides nucleate faster with the higher temperature. On the other hand, it can be concluded that the originally formed oxides began to gather together and turned into large particles. At the same time, the new small oxidation particles began to nucleate around the formerly formed oxides. 


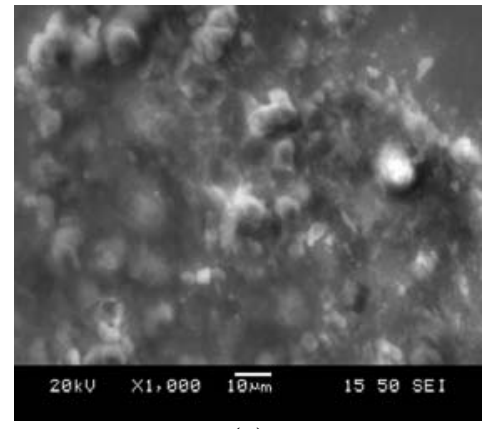

(a)

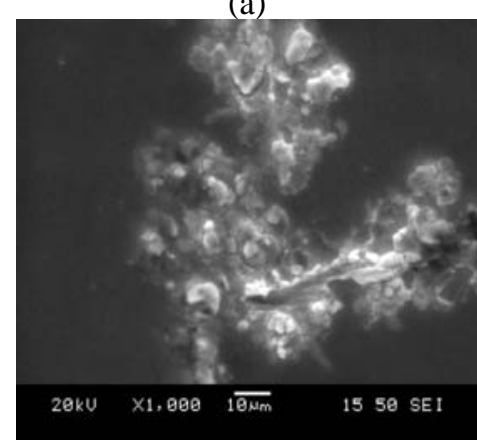

(b)

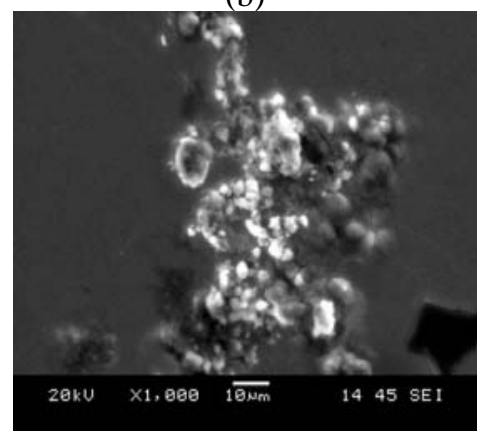

(C)

Fig. 1. The surface morphology of the amorphous ribbon annealed at different temperatures. (a) $360^{\circ} \mathrm{C}$, (b) $370^{\circ} \mathrm{C}$, (c) $380^{\circ} \mathrm{C}$.

Fig. 2 shows the ribbon surface morphology of the amorphous ribbon after annealed for $8 \mathrm{~h}$ with holding temperature $380^{\circ} \mathrm{C}$. The oxides morphology is round or bulk, which is similar with the ribbon annealed with shorter time. The differences are that the amount of the particles increased and the size turn larger. In addition, some cracks were found in the Fig. 2a. The crack locates at the bulk oxides, which is because that the coefficient of the thermal expansion for the oxides and the amorphous matrix is different. In order to further make clear of the difference of the surface morphology of the oxides, the oxygen content for the oxides with different morphologies was analyzed. It can be seen from Fig. 3 that the oxygen content for the morphology without a distinct outline is low. With the annealing time and temperature increasing, some round small particles formed. At the same time, the originally formed small round particles began to gather into a bulk oxide. The number in the figure represents the measurement location. Fig. 4 shows the oxygen content of each location with the number in Fig. 3. It can be seen that the oxygen content increased dramatically when the morphology of the oxides is clear. On the other hand, the oxygen content of the bulk oxide is similar to the small round particles. The mechanism of the oxidation of the amorphous ribbon is bulk diffusion controlled transition $[1,5]$.
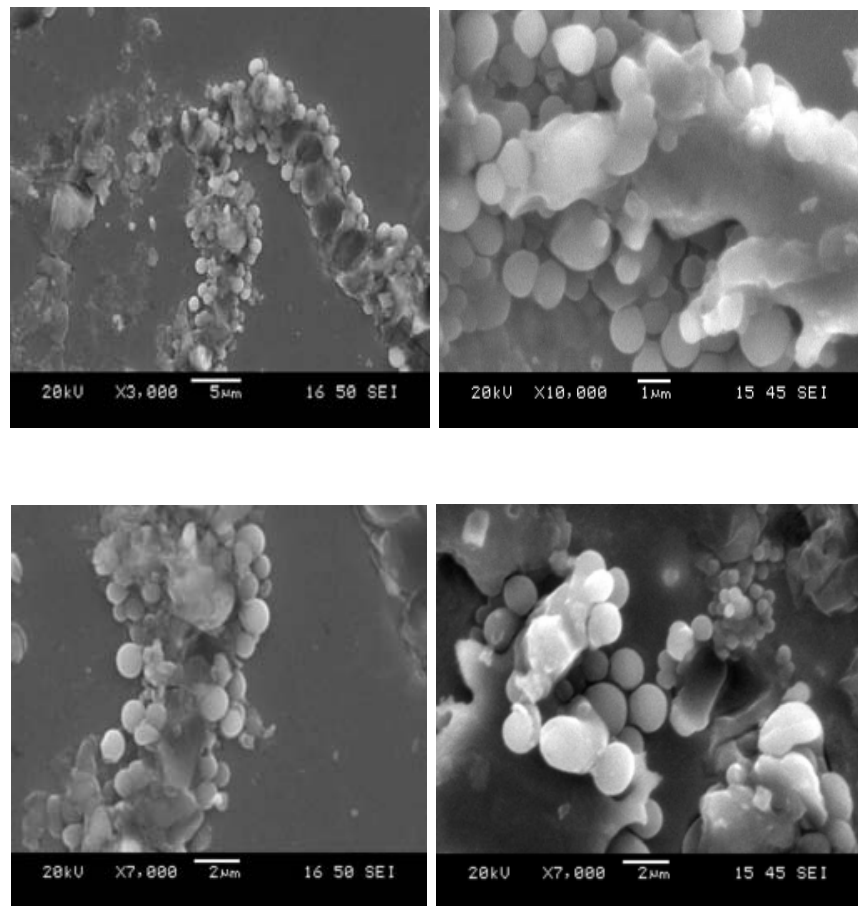

Fig. 2. SEM photos of the surface morphology for the ribbon annealed for $8 \mathrm{~h}$ and held at $380^{\circ} \mathrm{C}$.
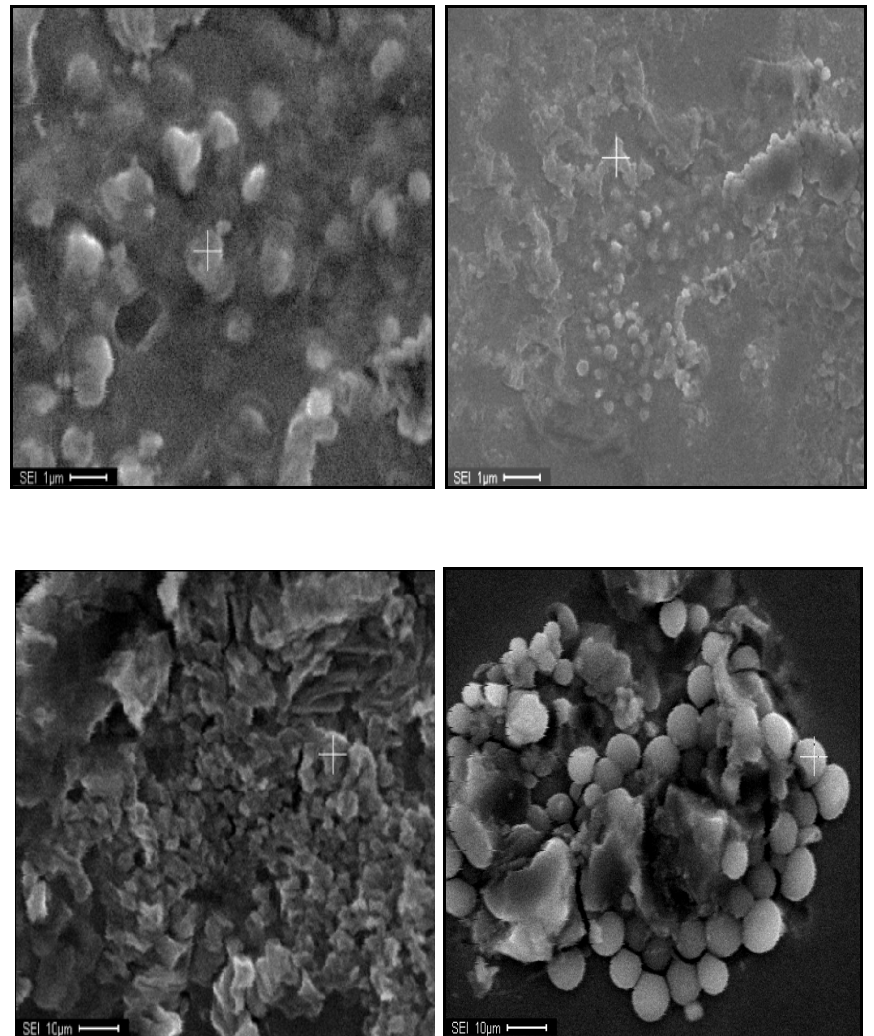

Fig. 3. The different morphology of the oxides formed at $380^{\circ} \mathrm{C}$. 


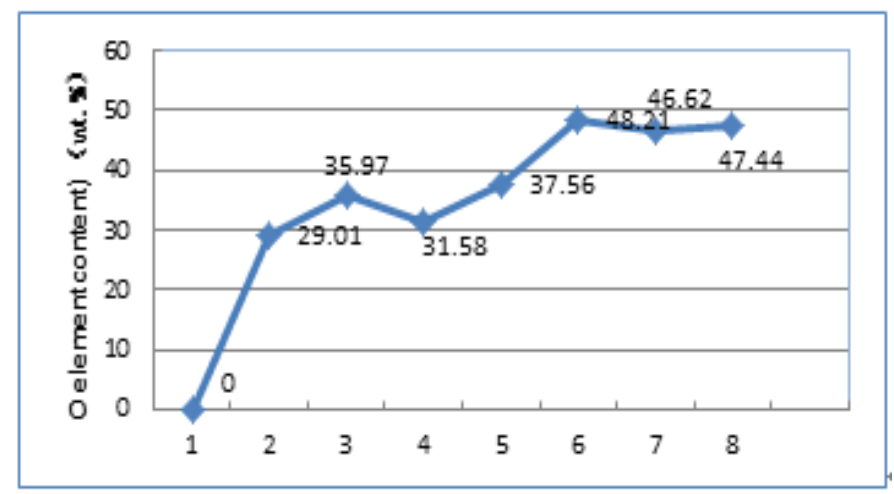

Fig. 4. Oxygen content of oxides at the different location in Fig. 3.

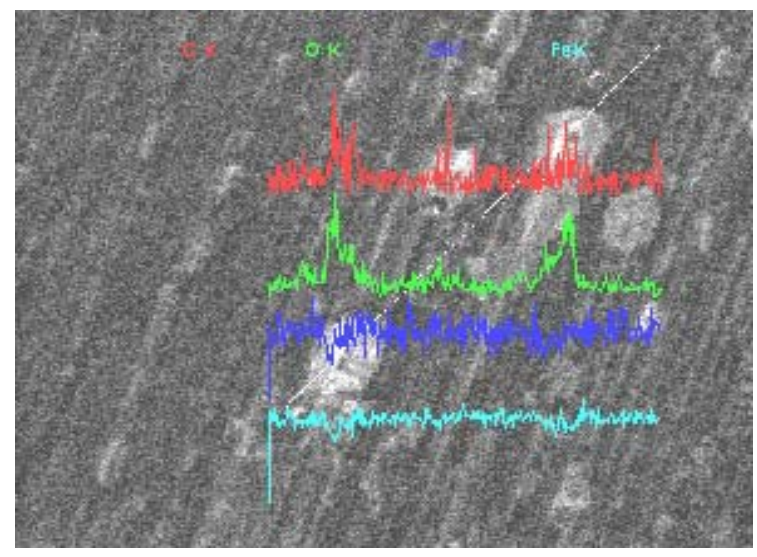

(a)

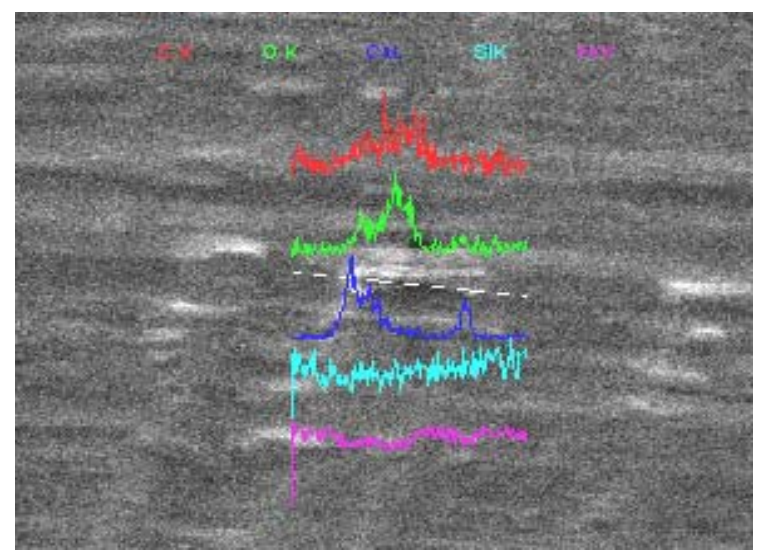

(b)

Fig. 5. The line scan of the ribbon annealed (a) and without annealed (b).

\section{B. Impurity}

For the amorphous ribbon, it is evitable that on the surface there exists some impurity. During the course of solidification, the copper particle on the copper roller can be taken into the surface of the ribbon. On the other hand, the existence of surface crystallization and composition segregation also can promote the happening of the oxidation $[6,7]$. Fig. 5(a) shows the line scan result of the annealed ribbon surface. It can be seen that on the roller surface of the ribbon there is some white dot phase formed. Through composition analysis by SEM, it is found that except oxygen element there is carbon element. Fig. 5(b) shows line scan result of the quench ribbon surface. Before annealing, there are carbon and oxygen element in the ribbon surface. According to the former analysis, it can be known that these outside impurities can promote oxidation happen. The outside impurity was taken into the surface of the ribbon during ribbon fabrication.

\section{Properties}

The formation of oxides can deteriorate the properties of the amorphous ribbon, which is because there is no magnetic domain structure in the oxides. During application of the material, it is difficult for the oxides to magnetization. Thus, the core loss of the surface oxidized ribbon increase. The conclusion was proved by experiment. The method is through adding a different amount of $\mathrm{N}_{2}$ per unit time into the heat treatment furnace during amorphous cores annealing with the magnetic field. The experiment result is shown in Fig. 6. It can be known that the magnetic properties of the amorphous cores heat treated with a large amount of $\mathrm{N}_{2}$ per unit time $\left(25 \mathrm{~m}^{3} / \mathrm{h}\right)$ is better, which is in good agreement with the analysis result. In a word, the oxide is not benefited for the improvement of the magnetic property of the amorphous ribbon.

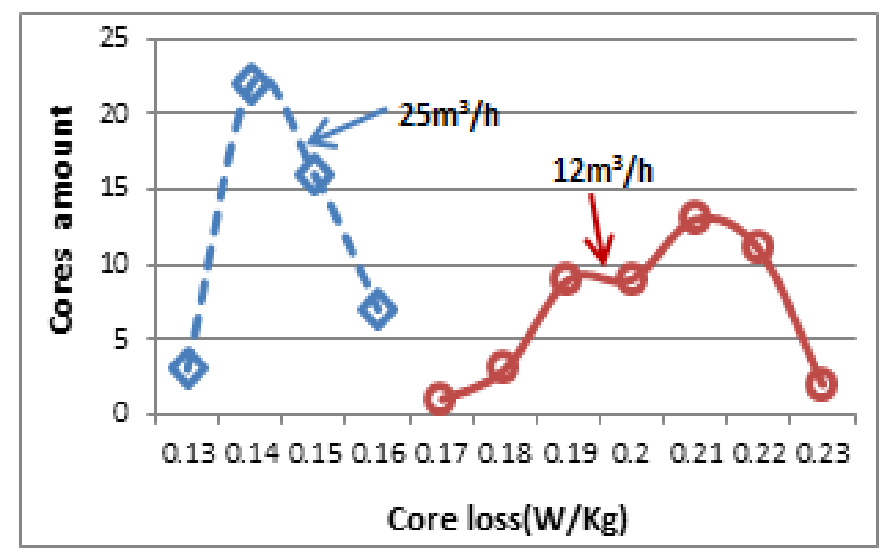

Fig. 6. The core loss of the amorphous cores heats treated with different amount addition of $\mathrm{N}_{2}$ per unit hour $\left(25 \mathrm{~m}^{3} / \mathrm{h}\right.$ and $\left.12 \mathrm{~m}^{3} / \mathrm{h}\right)$.

\section{CONCLUSION}

In this paper, the oxides morphology of the amorphous ribbon was investigated, which is circular originally and the oxides began to gather into a bulk oxide with the continuous of oxidization with the continuous oxidation. What's more the oxygen fraction of the oxide began to increase? The reason is that the element Fe, B, and Si don't oxidize at the same time. When the oxygen increases to an extent, the oxygen content began to be invariable. The experiment result proved this conclusion. On the other hand, the outside impurity offers the nucleation location of the oxide and promote the happen of oxidation. Thus in order to reduce the happen of the oxidation, one way is the reduction of the outside impurity and the other way is through addition protective gas into the heat treatment furnace. 


\section{REFERENCES}

[1] W. Kai, and I.F. Ren, "The oxidation behavior of an Fe61B15Zr8Mo7Co5Y2Cr2 bulk metallic glass at $650{ }^{\circ} \mathrm{C}$ in various oxygen-containing environments”, Intermetallics, vol. 17, pp. 165-168, 2009.

[2] W. Kai, and R.T. Huang. "Air oxidation of an Fe72B22Y6 bulk amorphous alloy at $600-700^{\circ} \mathrm{C}$ ”, Intermetallics, vol. 14, pp. 917-923, 2006.

[3] K. Hashimoto, and M.W. Tan, "Change in the surface composition of amorphous Fe-Cr-Mo-P-C alloys during air exposure”, Corros. Sci. vol. 37, pp. 331-341, 1995.

[4] Z. Dan, and K. Takenaka, "Effect of Si addition on the corrosion properties of amorphous Fe-based soft magnetic alloys”, J. Non-Cryst. Solids, vol. 402, pp. 36-43, 2014.

[5] E.Y. Kanga, and Y.H. Chung, "Research on the surface oxidation procedure of Fe-base metallic glass during wet oxidation treatment”, Mater. Sci. Eng. A, vol. 449-451, pp. 159-164, 2007.

[6] N. Morito, "Effect of carbon on surface crystallization of amorphous FeB-Si alloy induced by selective oxidation”, Mater. Sci. Eng. A, vol. 129, pp. 119-125, 1990.

[7] S. Myhra, J.C. Riviere, and L.S. Welch, "The early stage of room temperature oxidation of the amorphous alloys Fe70Cr15B15 and Fe85B15”, App. Surf. Sci. vol. 32, pp. 156 -172, 1988. 